\title{
Family relations in eating disorders: the Genogram as instrument of assessment
}

Carolina Leonidas ${ }^{1}$

Manoel Antônio Santos ${ }^{1}$
${ }^{1}$ Faculdade de Filosofia, Ciências e Letras de Ribeirão Preto, Universidade de São Paulo. Av. Bandeirantes 3900, Monte Alegre. 14040-901 Ribeirão Preto SP Brasil.carol_leonidas@ hotmail.com

\begin{abstract}
The present study aimed to evaluate the transactional patterns in families of women with EDs, through the use of the Genogram. The study included 12 girls and women linked to a multidisciplinary service. For the preparation of Genograms, a semistructured interview script was built that included specific topics regarding family relationships. Genograms' analysis followed the recommendations professed by the specialized literature. It was evident that families presented few skills in managing stressful events and resolving conflicts, resulting in emotional distance between members and vulnerability of bonds. The Genogram was proved useful as a resource for research and evaluation in the area of EDs, and the generated data was convergent with the literature. Results provide important subsidies for health professionals, since they indicate the need for care and development of therapeutic alliance with the family in the treatment for EDs.
\end{abstract}

Key words Eating disorders, Genogram, Family, Health assistance 


\section{Introduction}

The occurrence of a mental disorder in a family member causes the other family members to experience changes in life and in the household, including the experience of new emotions and responsabilities ${ }^{1}$. The way that family reacts to these new experiences and responsibilities exert direct influence on the evolution of the disorder and the welfare of the affected person ${ }^{2}$, which justify the need for studies that address family's experience with mental illness.

Currently, researches on family networks have documented the crucial role that social support, especially from family, carries on prevention and treatment of diseases ${ }^{3}$. In this interface of family support networks and promotion of health, Bullock mentions the reduction of mortality rates, improvement in management of symptoms of serious diseases and the increase of preventive care practices in health assistance ${ }^{3}$.

Eating disorders (ED) are health problems that have acquired more visibility in recent years. They can be defined as psychiatric conditions with multifactorial etiology ${ }^{4}$, i.e., several etiological and pathogenic factors interact in a complex way, precipitating and perpetuating the psychopathological condition. ED affect mainly women between 12 and 28 years old ${ }^{5}$. Family dynamics is one of the main factors involved in the genesis of symptoms. Morgan et al. ${ }^{4}$ claim that families that include a member with ED present very peculiar patterns of interaction. In families with an individual diagnosed with anorexia nervosa (AN), the standards include features such as rigidity, intrusiveness and avoidance of conflicts. In cases of bulimia nervosa (BN), family organization tends to be disrupted and disorganized, and women affected often complain of lack of affection and care $^{4}$. In addition, relations between father and daughter with ED are usually defined as emotionally distant and devoid of affection ${ }^{6}$.

However, it is noteworthy that considering family dynamics as part of the factors that predispose to the occurrence of ED is not intended to blame the family entirely for its occurrence ${ }^{7}$. On the contrary, researches addressing family usually seek to investigate how the interactions between family members can contribute to the maintenance of the disorder, so that health multidisciplinary team can plan interventions to index family members as allies in treatment. Thus, it becomes feasible to propose changes in family dynamics, especially in the way parents deal with the difficulties of the affected member, turning family into a valuable resource in health assistance ${ }^{8}$.

The inclusion of family in the treatment of ED was officially legitimized in the United States in 2006, with the launch of the Practice Guideline for the Treatment of Patients with Eating Disor$\mathrm{ders}^{9}$, a manual containing guidelines to be followed in the treatment of patients with ED, in which authors point out the relevance of including families, since evidence consistently suggests that interventions based on family care are associated with patients' recovery ${ }^{8}$.

In England, the National Institute of Clinical Excellence (NICE) has also developed a manual on treatment of ED, which was also emphasized the need to include family as care strategy ${ }^{10}$. Systemic approach proposes that family can be defined as a system, featuring a complex web of elements which are dynamically related in mutual interaction ${ }^{11}$. Accordingly, each family configures an interactional unit and each of its members is a subsystem of that unit. However, these members may also be characterized as systems themselves, constituted of several subsystems, since they bear physical, biological and psychological aspects of human life. Thus, each individual with their particular subsystems, helps composing the whole family, which is much more than the simple sum of each member's contribution.

The interaction established between individuals, in general, explains the individual behavior of each of the members, so that any changes that significantly affect any of them, affects everyone in variable degrees ${ }^{11}$. Serious and persistent illnesses, such as ED, are potentially disruptive and affect family as a whole, changing and disturbing its dynamics ${ }^{12}$. Furthermore, the onset of symptoms in one of the family members can also reinforce and crystallize the dynamics that rule relations between family members. For this reason, health assistance should include assessment of the strengths and weaknesses of families, in order to identify their coping resources.

In this scenario, the Genogram is one of the most useful tools that health professionals own to delineate the internal structure of families and map their strengths and vulnerabilities. It is noteworthy that social support is not restricted to family social network, but can also come from other networks such as friends, co-workers, neighbors, among others ${ }^{3}$. Therefore, as a research tool, the Genogram offers a cutout focused on family network, which constitutes only one among many other possibilities of social support that an individual can receive. 
The Genogram can be defined as a standardized graphic structure, universally used by genetics, to represent the internal structure of a family. The instrument was developed as a device to evaluate, plan and intervene on family functioning, in order to facilitate the interpretations of family experience ${ }^{11}$. It aims to gather information on members and family relationships through generations and configures an assessment tool used also by systemic family therapy ${ }^{13}$.

Nowadays, the Genogram has been widely used as data collection tool, especially by scientific research with qualitative approach that address family relations ${ }^{14,15}$. As instrument of assessment, the Genogram allows the detection of existing relationships in the family and, from the characterization of family structure and its position in the life cycle, also allows the researcher to develop hypotheses about the patterns of bonds and types of borders established within that context $^{12}$. In addition, the instrument also allows to identify possible triangulations within the family, understanding that triangulation refers to the relationships among three people, in which the way that one of them behaves depends and influences the behavior of the other two. The configuration of triangulations in families involves two people together against a third person, and aims to reduce the tension between the pair ${ }^{12}$.

Genogram's graphic layout resembles genealogical schemes: it is a family tree representing the family structure. Family members are placed in horizontal series that indicate generations, marriages are indicated by horizontal lines and the children by vertical lines ${ }^{11}$.

Considering these assumptions, the present study aimed to evaluate the transactional patterns in families of women with ED, through the use of the Genogram.

\section{Method}

This is a descriptive and exploratory study, with qualitative research approach.

\section{Participants}

Women diagnosed with ED $(\mathrm{n}=12)$, linked to a care service specialized in the treatment of $\mathrm{ED}$, located in a university hospital in the state of São Paulo. Participants' average age 27.7 years ( $\mathrm{SD}=5.18$ years). Eight of them had been diagnosed with AN purging type and four with BN. The inclusion criteria were: female patients, di- agnosed with ED (AN or BN), registered in multidisciplinary treatment regardless of age, education level, marital status, duration of illness and psychiatric comorbidity. The following exclusion criteria were also applied: evidence of serious injury in language or communication, cognitive or sensory loss (hearing) that could communication and understanding of the task, patient in recovery phase of treatment.

This is a non-probabilistic sample, in which the number of participants was defined according to the criteria of data saturation for qualitative research ${ }^{16}$, which proposes that the completion of data collection should be given at the time that obtained data do not add new information about the object of study.

To prevent participants' identification (Table 1 ), real names were replaced by fictitious names.

\section{Instruments}

Genogram and consultations to hospital records, which enabled the collection of participants' demographic and anthropometric data. To develop the Genograms, a script of specific questions was built, including the following topics: with whom participants lived; how she described the relations with these people; how did they relate to members of the family of origin (parents, brothers, uncles, grandparents, etc.); how did they relate to their children and husband (if applicable); how these relations were configured before the ED; if they would like that these relationships were different; if any members of the family distanced themselves from participants after the occurrence of the ED; if participants felt that they received family support to deal with the disorder, and if they would like the family to cope with the problem in a different way.

Literature that address families suggest the existence of "patterns of relationships crystallized within the family system"15, i.e., each family has particular and recurrent forms of relationships among its members, generating the effect that Wendt and Crepaldi ${ }^{15}$ named as transactional patterns. Such patterns can be identified by the Genogram and were defined as: harmonic relationship, very close relationship or over involvement, merged and conflictual relationship, alliance, conflictual relationship, vulnerable relationship, distant relationship, breakup, triangulation and coalition. The definition of transactional patterns will be further explained, according to the classification proposed by specialized literature $e^{15}$. 
Table 1. Characterization of participants according to age, diagnosis, anthropometric data (weight, height, baseline BMI and current BMI) and time of treatment.

\begin{tabular}{lclrrrrr}
\hline Participants & $\begin{array}{c}\text { Age } \\
\text { (years) }\end{array}$ & \multicolumn{1}{c}{ Diagnosis } & $\begin{array}{c}\text { Weight } \\
\mathbf{( k g})\end{array}$ & $\begin{array}{c}\text { Height } \\
(\mathbf{m})\end{array}$ & $\begin{array}{c}\text { Baseline } \\
\text { BMI } \\
\left(\mathbf{k g} / \mathbf{m}^{2}\right)\end{array}$ & $\begin{array}{c}\text { Current } \\
\text { BMI } \\
\left(\mathbf{k g} / \mathbf{m}^{2}\right)\end{array}$ & $\begin{array}{c}\text { Time of } \\
\text { treatment } \\
(\mathbf{m o n t h s})\end{array}$ \\
\hline Maria & 30 & AN binge eating/purging type & 49,1 & 1,64 & 17,8 & 18,3 & 22 \\
Grazieli & 20 & BN & 59,3 & 1,65 & 23,5 & 21,9 & 10 \\
Verônica & 27 & BN & 63,4 & 1,75 & 21,2 & 20,6 & 12 \\
Sofia & 27 & AN binge eating/purging type & 44,1 & 1,72 & 14,7 & 14,9 & 6 \\
Bárbara & 24 & AN binge eating/purging type & 56,4 & 1,60 & 21,9 & 21,9 & 1 \\
Carolina & 31 & BN & 101,3 & 1,65 & 36,1 & 37,2 & 84 \\
Fernanda & 40 & AN binge eating/purging type & 70,8 & 1,74 & 16,7 & 23,2 & 184 \\
Amanda & 22 & AN binge eating/purging type & 50,8 & 1,66 & 17,3 & 18,4 & 48 \\
Juliana & 30 & AN binge eating/purging type & 53,3 & 1,67 & 20,4 & 19,1 & 168 \\
Marina & 29 & BN & 60,7 & 1,69 & 20,0 & 21,5 & 60 \\
Giovana & 28 & AN binge eating/purging type & 47 & 1,71 & 15,9 & 15,9 & 1 \\
Ana & 24 & AN binge eating/purging type & 40,6 & 1,52 & 15,7 & 17,5 & 60 \\
\hline
\end{tabular}

- Harmonic relationship: can be defined as the emotional experience of union between family members, who share positive feelings regarding each other. In this transactional pattern there is reciprocity of interests, attitudes and values, as well as differentiation between members among themselves and their respective families of origin.

- Very close relationship or over involvement: relationships in which fusion and emotional dependency are predominant, characterizing members' psychological indiferentiation.

- Merged and conflictual relationship: marked by severe emotional dependency and the existence of frequent conflicts among Family members. There is indiferentiation between them and, consequently, individual lines become blurred.

- Alliance: characterized by connections based on invisible loyalties that, despite generating positive interactions, can interfere in the process of differentiation between members, even though in lower levels than in over involvement.

- Conflictual relationship: refers to relations that involve frequent arguments and disagreements in family enviroment, expressed by difficulties in communication, which involve disqualifications and disenpowerment of one another. These disfunctional patterns of communication can evolve to symmetric patterns, capable of generating physical violence.

- Vulnerable relationship: there are no explicit conflicts, but there is the possibility that opened conflicts may occur in adverse conditions or transition phases.

- Distant relationship: type of bonding usually found in families which are, from the affective point of view, disconnected and with rigid boundaries. There is little contact between members, especially the emotional kind of contact.

- Breakup: in this transactional pattern there is no contact between family members, even though they still maintain emotional connection.

- Triangulation: emotional setting involving three family members, in which the "triangulated" individual has the role of regulating the tension between the other two members. When there is no explicit conflict, that individual experiences feelings of insecurity or emotional distress. When conflict occurs, the embarrassment or distress is usually transferred to the members of the dyad, awakening sense of relief in the third one.

- Coalition: property of triads, defined by the union of two family members against a third party.

It is noteworthy that the transactional patterns, although recurrent, may be modified over time, especially during transitional phases and regulatory crises that family experiences throughout the family life cycle. These changes constitute important means by which members of the family can differentiate from each other and thus continue the family ${ }^{15}$. Accordingly, the 
transitions triggered by the illness may enhance both negative and positive changes in family network, depending on how family members face the tensions triggered in the process, and the predominant transactional patterns. Mental disorders, characterized by severe and persistent symptoms, can disturb family relationship patterns or accentuate preexisting dysfunctional relationships ${ }^{17}$.

Genogram's legends, developed in accordance with the standards proposed by the specialized literature ${ }^{15,18}$ is in Figure 1.

\section{Ethical considerations}

The study was approved by the Research Ethics Committee of the hospital where the study was conducted.

\section{Data collection}

The Genograms were applied individually during a single meeting with each participant, in a reserved room of the hospital. Joint work between participant and researcher was proposed during the instrument construction. Three generations of participants' family were included. The focus of the data collection started from the graphical creation of families for further exploration of the meanings attributed to relationships, extracted from family stories ${ }^{13}$.

Initially, it was requested that participants described their current family configuration. From that initial report, the researcher formulated questions about family relationships, inviting participants to share stories and events of family life $^{13}$, in order to investigate possible influences of ED symptoms in family dynamics. Names mentioned by the participants were noted and it was identified the type of relationship between participants and family members ${ }^{15}$, allowing detailed examination of the proximity and the pattern of interaction established with each member.

\section{Data analysis}

Genograms were prepared manually by the researcher during data collection. Thereafter, they were diagrammed using a specific program for creating graphic elements (CorelDRAW Graphics Suite). The interpretation of obtained results was based on the analysis guidelines recommended by the literature based on systemic approach $^{12,15,19}$. Data extracted from Genograms analysis were organized into thematic catego- ries, taking into account the core meanings that emerged - that is, the regularity of responses and convergent patterns of contents ${ }^{20}$ obtained both from reports, as from graphic illustrations of Genograms.

\section{Results and Discussion}

Next, five thematic categories will be presented and discussed, which were developed by the analysis of Genograms and participants' reports, raised during instrument application.

\section{Category 1. Merged and conflictual relationship with mother}

Type of relationship between mother and daughter that refers to mutual emotional dependence, in which both members of the pair experience difficulties to differentiate themselves of one another and to relate to each other in a more individualized way ${ }^{12}$. In this pattern of codependency, individual borders are blurred. This kind of relationship favors a wide range of conflict, since the pattern of fusional relationship between individuals is inevitably characterized by ambivalence and tension.

Seven participants in this study described their relationships with their mothers as fusional and conflictual, characterized by persistent need for the presence and frequent company of the mother. There is an alternation between the pressing need for closeness versus the need for distance, i.e. there is ambivalence between merged experiences and need for separation, denoting fear of differentiation and loss of identity limits. For this reason, human relations become threatening, leading to withdrawal that can sometimes be confused with contempt. However, these participants felt excessively charged by mothers, which aroused intense feelings of helplessness and incomprehension. Five participants reported alliance with the mother, without expression of manifest conflicts.

When asked about the relationship with the mother, those participants who described fused and conflictual relationships could explain them only through the relationship to food, as can be seen in the following report:

[...] My mother even says, when... "My God, you are eating too much. Stop eating for a while". Nowadays I... I don't really care anymore, you know? With what she says. I look at her and I start laughing. However, if it was a few months ago, I 


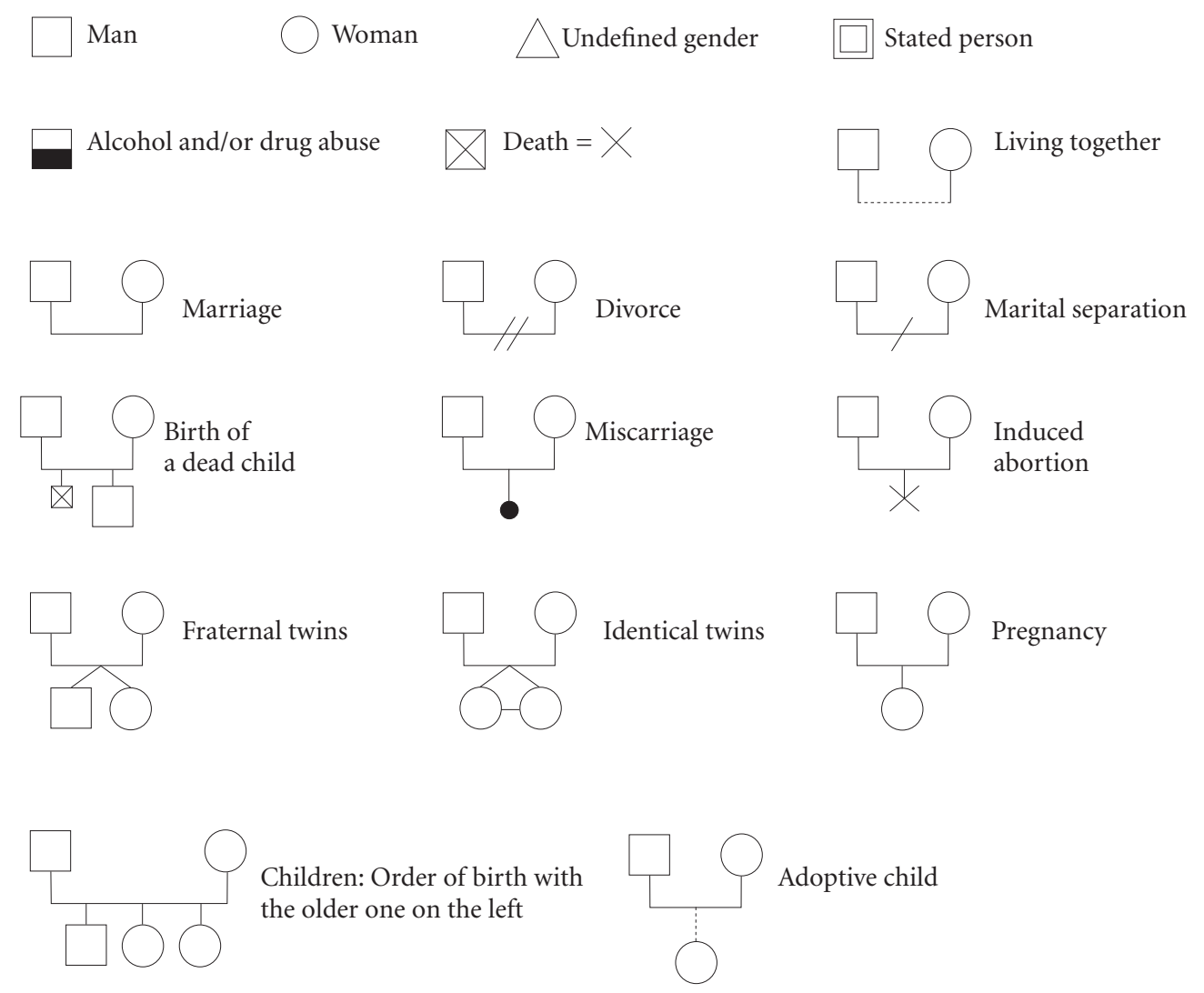

Relationships:

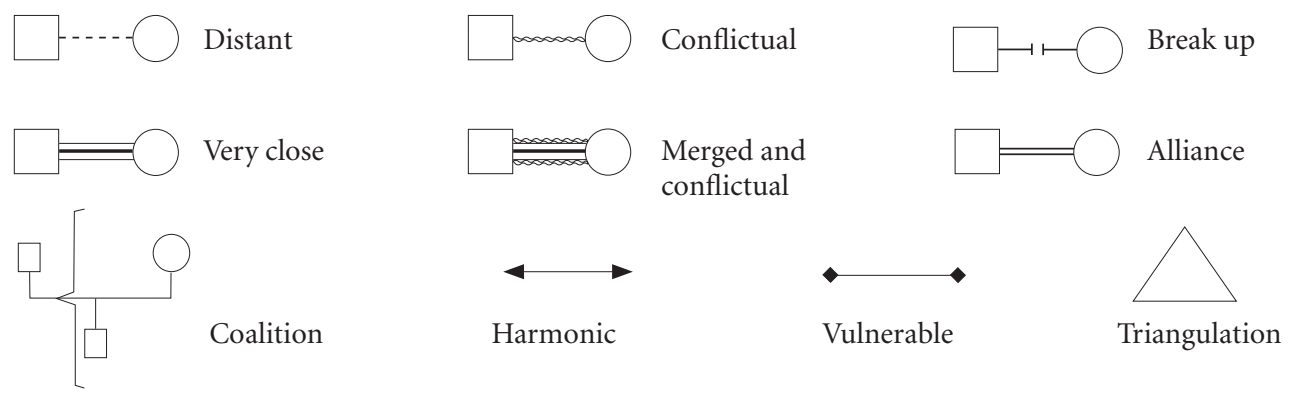

Figure 1. Legends of the Genogram, according to the specialized literature ${ }^{14,17}$.

would say: "My God, my mom is saying that I'm eating too much", you know? When it's not actually true... (Ana)

Ana has a very reticent speech, indicating difficulty to express the feelings aroused by her mother's comments. However, it is possible to infer the anguish aroused by the way the mother expressed her discomfort with how her daughter fed. The patient reports that in the past, when exposed to her mother's comments and rebuke regarding her feeding behavior, she felt her self-image being attacked and, therefore, her self-es- 
teem was depreciated. Ana's Genogram (Figure 2) illustrates, in a sense, participant's report during the interview. It is evident fusional and conflictual relationship with mother, vulnerable relationship with father and perception of emotional distance between the parental couple. It is also evident the alliance with the siblings. Participants' relationships with father and siblings will be better addressed in the following categories, as well as the relationship between the parental couple.

The available literature on the relationship between mother and daughter affected by an $\mathrm{ED}$ is convergent in proposing the hypothesis of a standard fusional type of interaction, which would involve the experience of ambivalent and conflictual emotions. These relationships are built on a process of psychological indifferentiation, characterized by the non-recognition of individuality. The relationship of fusion and indifferentiation in ED is commonly marked by ambivalence between love and hate, as mother and daughter love each other and want to stay close, but at the same time trying, unsuccessfully, to separate and individuate ${ }^{21}$. Mother and daugh- ter become dependent on each other and, on the other hand, feel fear and horror to this codependency, which implies a recurring search for the completeness and supplementation of an inner emptiness that never seems to be fulfilled ${ }^{22}$.

\section{Category 2. Distant and/or vulnerable relation with father}

Five participants described their relationships with their fathers as vulnerable, since there once have been severe conflicts and tense situations with father figure. However, at the moment of the interview, the relationship was peaceful. The denomination "vulnerable relationship" necessarily implies on the possibility of relapse of conflicts in adverse situations ${ }^{15}$. Accordingly, it was evident that, among participants, the father-daughter relationship was configured by superficial interactions, which did not enable the expression of emotions and did not offer support to cope with distressful experiences, since this type of opening in relationship could contribute to generate new doubts, difficulties and, consequently, new conflicts.

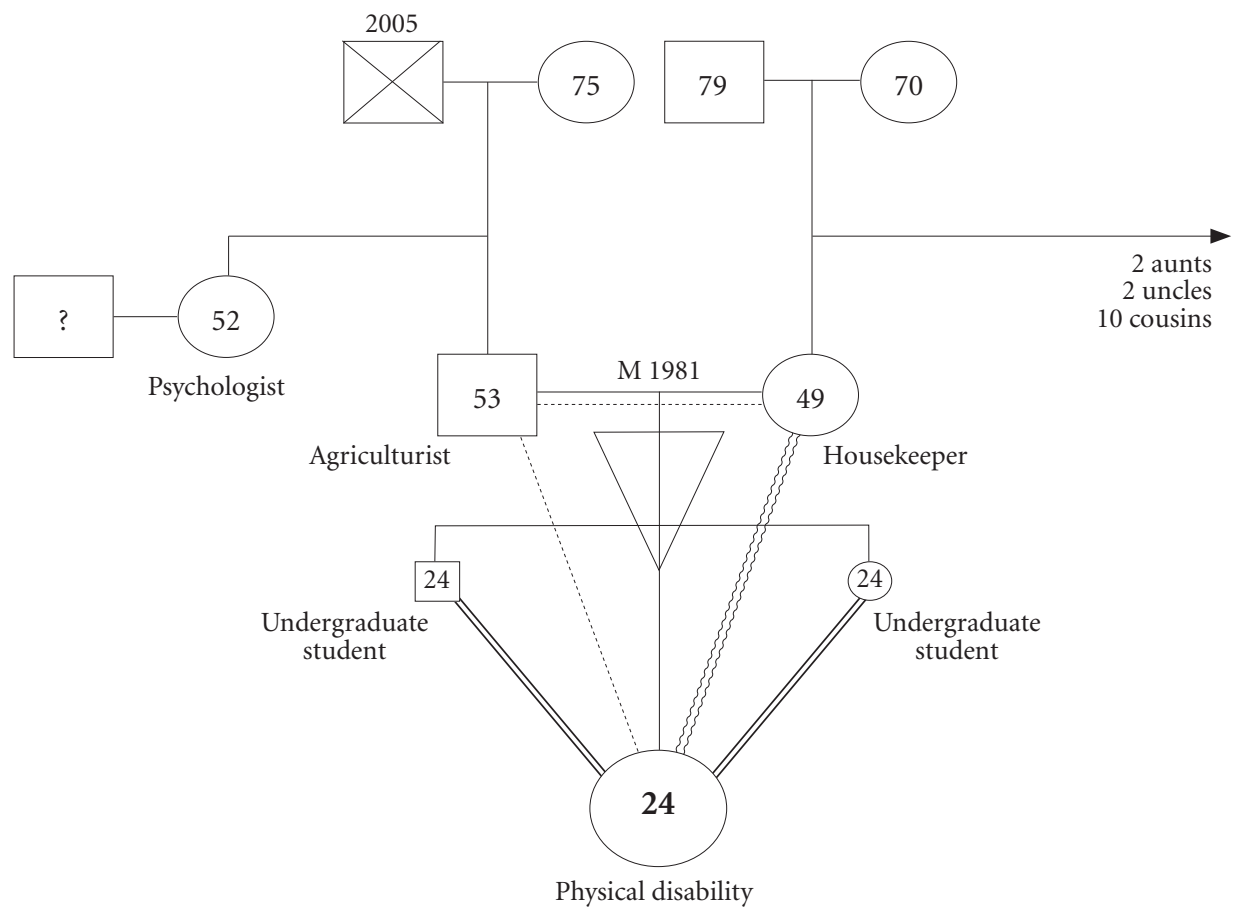

Figure 2. Ana's Genogram. 
I remember that when I was ten, more or less, he [father] said that I was chubby... He said: "You're chubby, something like that, when you grow up you won't get a boyfriend, you'll be just like F.", F. was a friend of my sister who was fat and did not have a boyfriend because of that. After that I stopped eating... Understand? I was... Then I started dieting, started losing weight... The more I lost weight, the more I wanted to lose weight. (Juliana)

The relationship with father figure was described as distant by three participants, and conflictual by two. Carolina and Amanda reported not caring about father's withdrawal, as if this type of bonding had already been naturalized within family dynamics. Ana, in turn, wished that family members were emotionally closer and that they could talk more with each other. However, the participant reported believing that little dialogue is part of her family's profile, and that this pattern is not changeable.

So, I don't talk very much with my father, we just talk about other people... Other people's stuff, sometimes he tells me about someone that I know, something like this... But he doesn't talk much, there's not a dialogue. (Ana)

Maria characterizes the relationship with her father as friendly, respectful, but not intimate. She reported that she had experienced several conflicts with her parents in the past, especially when the symptoms of ED were more severe, because they tried to make her see things, and she did not accepted it.

Well, I think they had to fight with me a lot. You know, to make me... Get to treatment... To make me see things... It was a constant struggle, you know? It was... It was a fight to take me to psychotherapy, it was a fight to make me eat, it was a fight to make me take my medication... So, for them... It was very complicated. (Maria)

Maria's family structure and transactional patterns are presented in Figure 3.

Two participants had lost their fathers at the time of data collection. Data extracted from Genograms regarding father-daughter relationships were convergent with findings from literature, which characterize this relation as typically superficial $^{23}$. Father is described as a blurred and tenuous figure, and also as weak, passive, with obsessive structured personality. On the other hand, when compared to mothers, fathers are presented as warm and permissive, interfering very little on family decisions ${ }^{24}$.

\section{Category 3. Diversity in fraternal relations}

Four participants from this study reported keeping happy relationships with their siblings, and two characterized these relations as alliance. Happy relationships include feelings of union and reciprocity, and also include clear differentiation between members ${ }^{15}$. Alliances also refer to union, but in this case there might be difficulties in the process of differentiation.

However, five participants described their relationships with siblings as distant, and three described them as conflictual. These distances and conflicts were related to the feeling of not being comprehended by siblings, not receiving support and considering that everyting was for them [siblings] (Grazieli).

Yeah... I'd like us to be closer. Understand? Even when we're together, we're like... Arguing, you know? We're apart. (Fernanda)

It is noteworthy that three participants maintained different types of relationships with each sibling, i. e., they reported alliance with a brother and conflictual relation with a sister, which showed multiple possibilities regarding types of relationships within family networks.

Literature shows very few data regarding fraternal relations of individuals with ED. Siblings may influence the disorder in a positive or negative way ${ }^{25}$. This influence may happen through the active presence of siblings in the family, the variable ways that they may react to the disorder and also through the level of influence that they exert over their parents. Many factors may affect siblings' influence, including: their comprehension over ED, prevalent type of relationship before the occurrence of the disorder, whether siblings' involvement was stimulated or not by parents and the affected daughter, siblings' characteristics of personality and family dynamics, as well as professional interventions that include siblings in health assistance.

Quality of life of siblings is usually negatively affected by sister's $\mathrm{ED}^{26}$. Authors point out to the following effects of the disorder over siblings: wish to understand the ED, consciousness of disorders' typical behaviors and thoughts, difficulties to understand obsessive behaviors not related to the ED, increasing family conflicts, compassion and concern about the affected sister, feelings of loss and self-sacrifice, oppressive sense of responsibility for the sister and sensation that the $\mathrm{ED}$ is omnipresent in all aspects of their lives. 


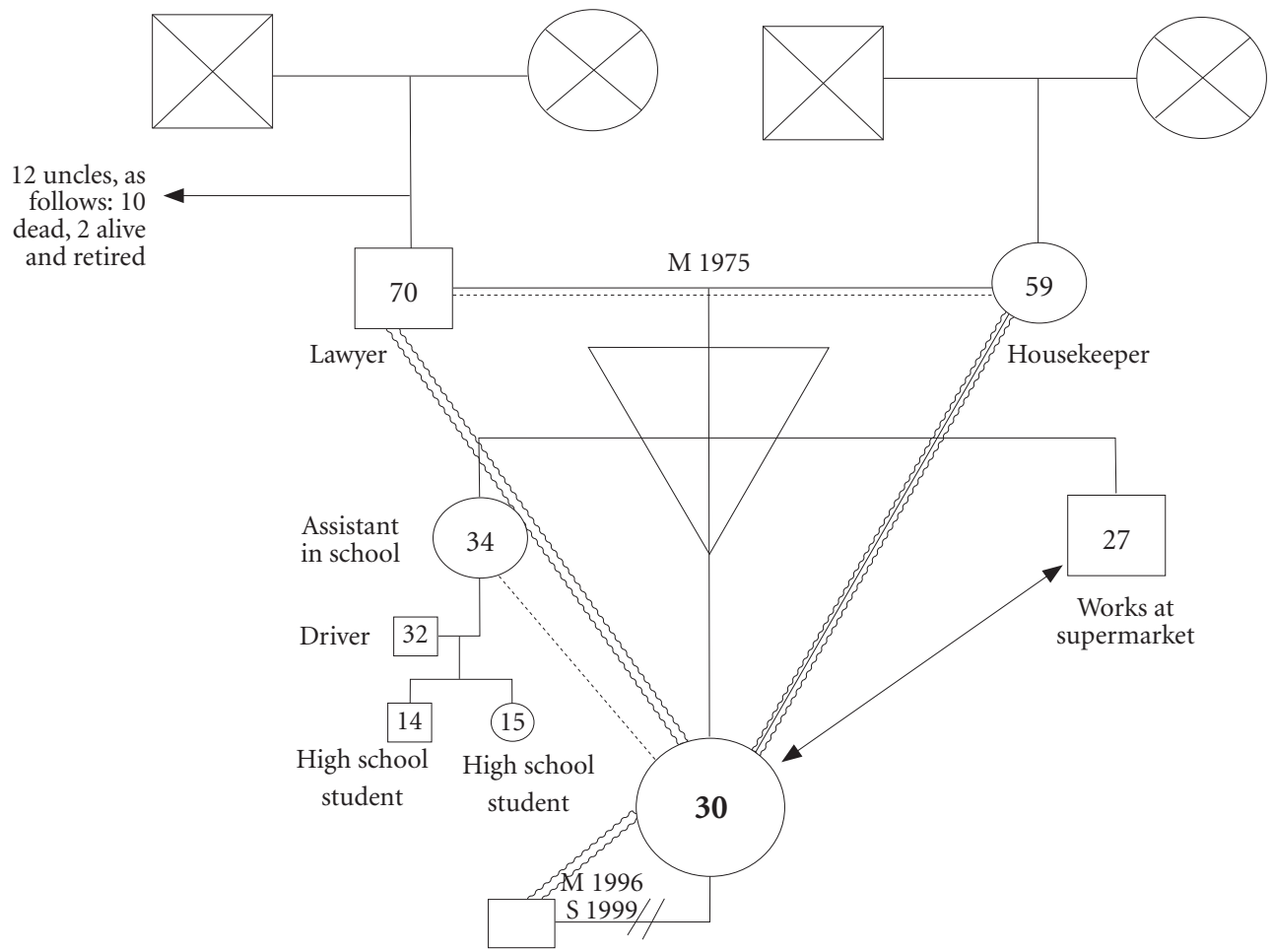

Figure 3. Maria’s Genogram.

\section{Category 4. Parental couple: impoverishment of the bond and triangulation}

Genograms' analysis showed the existence of conflicts between parents of eight participants, which appear to have culminated in couple's emotional withdrawal and, in the case of two participants, in separation. These data corroborate specialized literature, which suggests and relationships within families with a member affected by an ED are fragile, with predominance of problematic bonds, frequent arguments, triangulation and negative relation with food ${ }^{4}$.

Triangulation, a phenomenon strongly present in families of individuals with $\mathrm{ED}^{4}$, was identified in the analysis of eight participants of this study. It corresponds to the connection between three people, in which one's behavior depends and influences the other two. Triangulation's configuration in families involve two people united when facing a third one, aiming to reduce the tension between the couple. It is believed that for a health development of an individual, it is neces- sary that family members can differentiate themselves from one another, especially regarding the ability of taking charge and making decisions on their own, independently of relations established with other people ${ }^{12}$. An example of triangulation can be viewed in Verônica's Genogram (Figure 4). In this case, it is noteworthy that the participant maintained an alliance with her mother, forming a couple that acts against a third member, the father, with whom the participant has a vulnerable relationship. The existence of conflicts between the parental couple can also be observed.

In the presence of $\mathrm{ED}$, family relations present typical patterns of anxiety, ambivalence and excessive concern, especially in mother-daughter relationship, which usually result in the exclusion of a third member - the father, characterizing triangulation. Women with ED experience frequent conflicts between their parents, which can be real or imminent, and they also feel trapped in the middle of these conflicts and coerced to take the side of one parent ${ }^{4}$.

Accordingly, it is hipothesized that the over involved relationship between mother and 


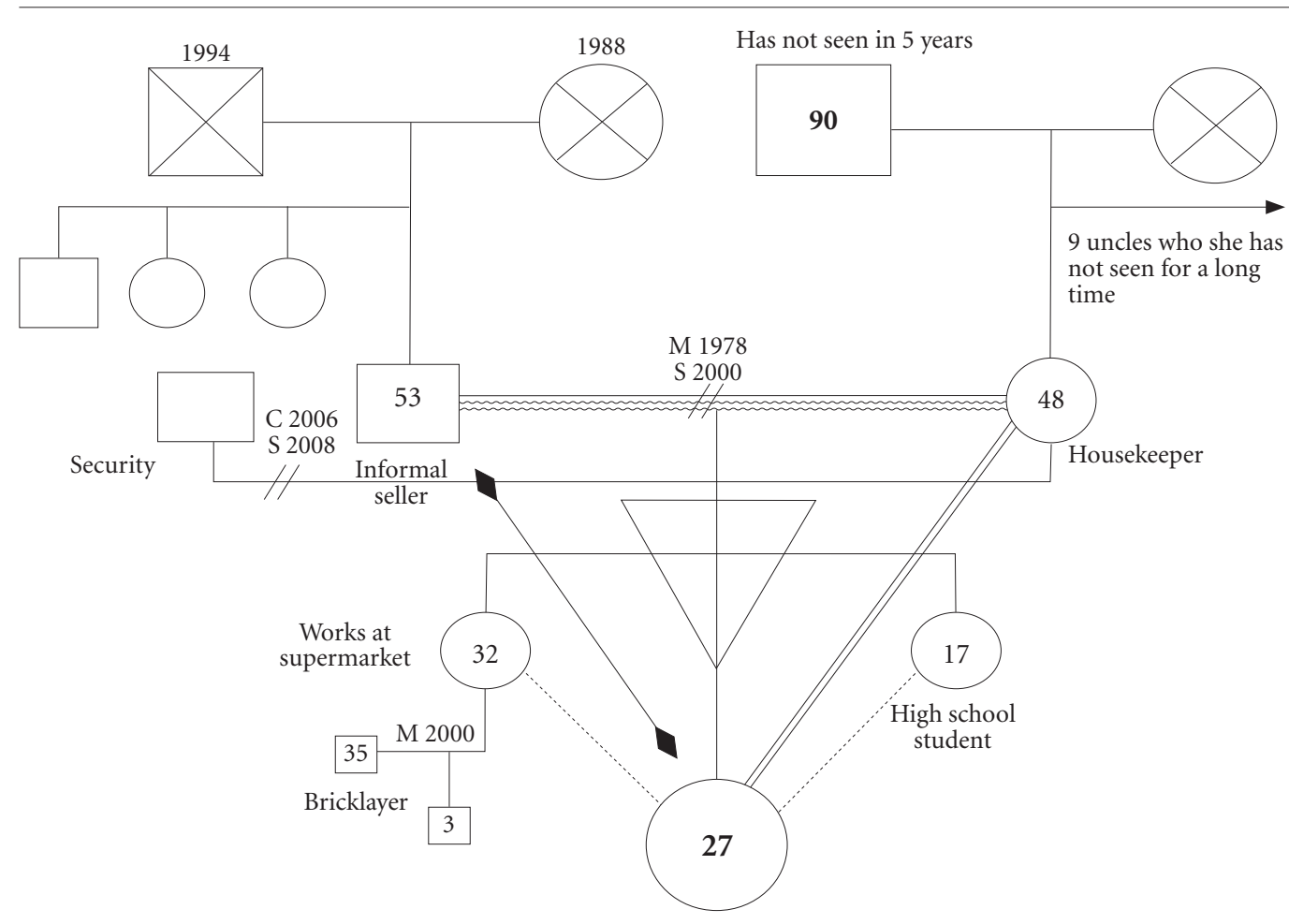

Figure 4. Veronica’s Genogram

daughter is a reflex of implicit or ostensive tensions between the parental couple, which are covert by daughter's ED. Thereby, it can be considered that the psychopathological disorder works as a "distraction", to parents, from their own covert conflicts ${ }^{12}$.

\section{Category 5. Constituted family: conflicts and vulnerability}

Only three participants were married, and one of them (Maria) did not have children. She characterized the relationship between her and her ex-husband as very conflictual, since he did not accept her way, her personality. The relationship lasted for three years. Carolina, in turn, reported that she had two marital relationships, the first of which lasted for two years and the second for 13 years. Both relationships were defined as very troubled, i. e., there were many struggles between the couple, especially regarding husband's episodes of adultery. Marina also defined her marriage with her ex-husband as troubled, es- pecially because of the extramarital relationships that he maintained many women, including participant's cousin. It is noteworthy the convergence of the reports regarding the existence of conflicts and severe distrust in marital relations, which culminated in breakups.

Carolina had two children, one of each marriage. She reported having the habit of being physically violent to the older child, due to the fact that she used to "outburst" her anger and aggressive feelings towards him. When her second child was born, the participant reported that she could cope better with her aggressiveness, so that the violent acts against the older child were ceased. By the time of data collection, Carolina's relationship with her older child was less conflictual, characterized as vulnerable.

Marina also had two children: a 11 year-old daughter and a three year-old son. She mentioned her son very few times, but when she referred to her daughter it was evident a very dysfunctional relationship, characterized by the Genogram as merged and conflictual: Marina clearly expressed 
desire to have a body similar to her daughter's, which was followed by hate of her own body and, consequently, her daughter's.

Personality of women with AN is usually distinguished by traits of inferiority, inadequacy and insecurity, followed by perfectionism, obsessiveness, compulsivity, negative emotions, withdrawal and avoidance conducts ${ }^{27-29}$. On the other hand, women with $\mathrm{BN}$ usually present impulsive behaviors, histrionic traits and borderline personality disorders as comobidity ${ }^{30,31}$, besides maladaptative thoughts and emotions, which commonly result in chaotic attitudes that undermine many aspects of life, such as studies, work and romantic relationships ${ }^{32,33}$.

Considering these assumptions, it is inferred that personality traits play a crucial influence in participants' difficulties to establish and maintain healthy relationships with people from their environment, especially those with whom they have daily contact, such as husband and children. Introversion and withdrawal, as well as impulsive behaviors and chaotic attitudes, seem to culminate in difficulties of interaction, which result in shortage of members in their social networks ${ }^{32,34}$, in performing very few leisure activities and in experiencing conflicts in marital, parental and fraternal relationships. Given the existing association between social interaction and quality of life $\mathrm{e}^{35}$, it is possible that the impoverishment of social and family networks and the lack of leisure activities are related to the chronicity of the ED.

\section{Final remarks}

The present study aimed to evaluate transactional and relational patterns in families of women with ED, through the use of the Genogram. Data collected from the application of the instrument were convergent with the specialized literature regarding the dynamics of family relations of individuals with ED. The use of the Genogram allowed the graphic illustration of the existing types of relationships within these families, enabling visualization the bonding patterns. The results are similar to the studies available on the literature.
In general, it was observed that participants' relationship with their mothers was based on a very close alliance that, in most cases, configured merged relationship and resulted in indiferentiation between mother and daughter, causing numerous conflicts between the couple. However, the relationship with father figure emerged in participants' reports as vulnerable and/or emotionally distant, prevailing superficial contact and impoverished bond.

This study allows to enlarge the accumulated knowledge since it provides evidence that family relationships in ED are distinguished by impoverishment and vulnerability of bonds. Therefore, participants perceive their families as lacking emotional resources to deal with conflicts and difficulties aroused by the ED. Failure to reset relations after the occurrence of stressful events seems to have resulted in impairment of family dynamics, which for some member is configured for merged and conflictual relationships, and to other members is characterized by emotional distance, vulnerability and/or struggles.

The study enabled the examination of the Genogram's potential to investigate family networks of patients with ED. The use of the Genogram as instrument of research in health was valuable in identifying the resources and constraints of family networks of patients with chronic illnesses, allowing the planning of interventions that include family as an ally in treatment. However, it is noteworthy that the use of the instrument has limitations, since it provides a momentary view, once human relationships - not just family - are dynamic and are in constant motion and change. Accordingly, the results of this study should not be viewed as static, but concerning to a specific time of participants' life course. Furthermore, these results regard to participants' perception of the prevalent relational patterns in their families. The analysis undertaken in this study is limited to verbal language and to how only one of the family members comprehends the existing dynamics in that context. In this sense, it is recommended that future studies include the family as a whole in the construction of the Genogram. 


\section{Collaborations}

C Leonidas designed the study, conducted data collection and analysis, and contributed to the final draft of the article. MA Santos designed the study, contributed to data analysis, reviewed the manuscript and worked on general supervision of the article.

\section{Acknowledgments}

To financial support from São Paulo Research Foundation (FAPESP), through the award of Master's scholarship to the first author, supervised by the second author. To financial support from National Council for Scientific and Technological Development - CNPq, through Research Productivity Scholarship awarded to the second author. 


\section{References}

1. Galera SAF, Zanetti ACG, Ferreira GCS, Giacon BCC, Cardoso L. Pesquisas com famílias de portadores de transtorno mental. Rev Bras Enferm 2011; 64(4):774778.

2. Silva I, Pais-Ribeiro J, Cardoso H, Ramos H, Carvalhosa SF, Dias S, Gonçalves A. Efeitos do apoio social na qualidade de vida, controle metabólico e desenvolvimento de complicações crônicas em indivíduos com diabetes. Psicol Saúde Doenças 2003; 4(1):21-32.

3. Bullock K. Family social support. In: Bomar PJ, editor. Promoting health in families: Applying research and theory to nursing practice. Philadelphia: Saunders; 2004. p. 141-161.

4. Morgan CM, Vecchiatti IR, Negrão AB. Etiologia dos transtornos alimentares: aspectos biológicos, psicológicos e socioculturais. Rev Bras Psiquiatr 2002; 24(3):1823.

5. Vale AMO, Kerr LRS, Bosi MLM. Comportamentos de risco para transtornos de comportamento alimentar entre adolescentes do sexo feminino de diferentes estratos sociais do Nordeste do Brasil. Cien Saude Colet 2011; 16(1):121-132.

6. Dallos R, Denford S. A qualitative exploration of relationship and attachment themes in families with an eating disorder. Clinl Child Psychol Psychiatry 2008; 13(2):305-322.

7. Scorsolini-Comin F, Souza LV, Santos MA. A construção de si em um grupo de apoio para pessoas com transtornos alimentares. Estud Psicol 2010; 27(4):467-478.

8. Souza LV, Santos MA. Familiares de pessoas diagnosticadas com transtornos alimentares: Participação em atendimento grupal. Psicol Teor Pesqui 2012; 28(3):325334 .

9. American Psychiatric Association. Practice guideline for the treatment of patients with eating disorders. Washington: American Psychiatric Association; 2006.

10. National Institute of Clinical Excellence. National clinical practice guideline: core interventions in the treatment and management of anorexia nervosa, bulimia nervosa, and related eating disorders. London: National Institute for Clinical Excellence; 2004.

11. Wright L, Leahy M. Enfermeiras e família: um guia para avaliação e intervenção na família. $3^{\text {a }}$ ed. São Paulo: Roca; 2002.

12. McGoldrick M, Gerson R, Petry S. Genograms: assessment and intervention. $3^{\mathrm{a}}$ ed. Nova York: W. W. Norton Co Inc; 2008.

13. Krüger LL, Werlang BSG. O genograma como recurso no espaço conversacional terapêutico. Rev Aval Psicol 2008; 7(3):414-426.

14. Gerson R, McGoldrick M. Genogramas en la evolución familiar. Barcelona: Gedisa; 1993.

15. Wendt NC, Crepaldi MA. A utilização do genograma como instrumento de coleta de dados na pesquisa qualitativa. Psicol Reflex Crit2008; 21(2):302-310.

16. Carter B, McGoldrick M. As mudanças no ciclo de vida familiar: uma estrutura para a terapia familiar. $2^{\mathrm{a}} \mathrm{ed}$ Porto Alegre: Artmed; 2011.

17. Guest G, Bunce A, Johnson L. How many interviews are enough?: An experiment with data saturation and variability. Field Methods 2006; 18(1):59-82.
18. McGoldrick M, Gerson R. Genetogramas e o ciclo de vida familiar. In: Carter B, McGoldrick M, organizadoras. As mudanças no ciclo de vida familiar: uma estrutura para a terapia familiar. $2^{\mathrm{a}}$ ed. Porto Alegre: Artes Médicas; 1995.

19. Moré CLOO. As redes pessoais significativas como instrumento de intervenção psicológica no contexto comunitário. Paidéia 2005; 15(31):287-297.

20. Minayo MCS. O desafio do conhecimento: pesquisa qualitativa em saúde. São Paulo, Rio de Janeiro: Hucitec, Abrasco; 1994.

21. Bruno CANB. Anorexia: um ponto de vista freudiano. In: Bruno CANB, organizadora. Distúrbios alimentares: uma contribuição da psicanálise. Rio de Janeiro: Imago; 2011. p. 49-60.

22. Miranda MR. A complexidade da relação mãe-filha nas patologias dos contrários. In: Bruno CANB, organizadora. Distúrbios alimentares: uma contribuição da psicanálise. Rio de Janeiro: Imago; 2011. p. 123-154.

23. Nodin L, Leal IP. Representações paternas na anorexia nervosa. Anal Psicol 2005; 23(2):201-208.

24. Marcelli O, Braconnier A. Manual de psicopatologia do adolescente. Porto Alegre: Artes Médicas; 1989.

25. Honey A, Clarke S, Halse C, Kohn M, Madden S. The influence of siblings on the experience of anorexia nervosa for adolescent girls. Eur Eat Disord Rev 2006; 14(5):315-322.

26. Areemit RS, Katzman DK, Pinhas L, Kaufman ME. The experience of siblings of adolescents with eating disorders. J Adolesc Health 2010; 46(6):569-576.

27. Cassin SE, Von Ranson KM. Personality and eating disorders: a decade in review. Clin Psychol Rev 2005. 25(7):895-916.

28. Nilsson K, Sundbom E, Häglöf B. A longitudinal study of perfectionism in adolescent onset anorexia nervosa, restricting type. Eur Eat Disord Rev 2008; 16(5):386394.

29. Peres RS, Santos MA. Contribuiç̃oes do Desenho da Figura Humana para a avaliação da imagem corporal na anorexia nervosa. Medicina (Ribeirão Preto) 2006; 39(3):361-370.

30. Kaye W. Neurobiology of anorexia and bulimia nervosa. Physiol Behav 2008; 94(1):121-135.

31. Vindreau C. A bulimia na clínica psiquiátrica. In: Brusset B, Couvreur C, Fine A, organizadores, A bulimia. São Paulo: Escuta; 2003.p. 81-102

32. Limbert C. Perceptions of social support and eating disorder characteristics. Health Care Women Int 2010; 31(2):170-187.

33. Oliveira EA, Santos MA. Perfil psicológico de pacientes com anorexia e bulimia nervosas: a ótica do psicodiagnóstico. Medicina (Ribeirão Preto) 2006; 39(3):353-360.

34. Leonidas C, Crepaldi MA, Santos MA. Bulimia nervosa: uma articulação entre aspectos 34. emocionais e rede de apoio social. Psicol teorprat 2013; 15(2):62-75.

35. Sluzki CE. A rede social na prática sistêmica: Alternativas terapêuticas. São Paulo: Casa do Psicólogo; 1997.

Article submitted 16/06/2014

Approved 08/10/2014

Final version submitted 10/10/2014 
